\title{
Determination of Chondroitin Sulfate Content in Raw Materials and Dietary Supplements by High-Performance Liquid Chromatography with UV Detection After Enzymatic Hydrolysis: Single-Laboratory Validation First Action 2015.11
}

\author{
Sharon L. Brunelle \\ Brunelle Biotech Consulting, 14104 194th Ave NE, Woodinville, WA 98077
}

\begin{abstract}
A previously validated method for determination of chondroitin sulfate in raw materials and dietary supplements was submitted to the AOAC Expert Review Panel (ERP) for Stakeholder Panel on Dietary Supplements Set 1 Ingredients (Anthocyanins, Chondroitin, and PDE5 Inhibitors) for consideration of First Action Official Methods ${ }^{\mathrm{SM}}$ status. The ERP evaluated the single-laboratory validation results against AOAC Standard Method Performance Requirements 2014.009. With recoveries of $100.8-101.6 \%$ in raw materials and $105.4-105.8 \%$ in finished products and precision of $0.25-1.8 \% \mathrm{RSD}_{\mathrm{r}}$ within-day and $1.6-4.72 \% \mathrm{RSD}_{\mathrm{r}}$ overall, the ERP adopted the method for First Action Official Methods status and provided recommendations for achieving Final Action status.
\end{abstract}

Under a contract from the National Institutes of Health Office of Dietary Supplements, AOAC INTERNATIONAL created the Stakeholder Panel on Dietary Supplements (SPDS), whose mission is to establish voluntary consensus standards for 25 high-priority ingredients. The high-priority ingredients are those for which scientifically valid methods were lacking at the time. As with all stakeholder panels, AOAC engaged industry, government, and academic experts to populate the panel and drive consensus.

In September 2014, SPDS finalized and approved Standard Method Performance Requirements (SMPR ${ }^{\circledR}$ ) for determination of total chondroitin sulfate (CS) in dietary ingredients and supplements, SMPR 2014.009 (1). This SMPR was intended to outline the minimum recommended performance characteristics for a reference method for routine analysis or dispute resolution. SMPRs are used by AOAC Expert Review Panels (ERPs) as a basis for evaluating candidate methods.

A call for methods was issued by AOAC on January 13, 2015, to select and evaluate methods for CS in dietary supplements according to SMPR 2014.009. The ERP for SPDS

Corresponding author's sbrunelle@ aoac.org.

Comments can be sent directly to the corresponding author or methodfeedback@aoac.org

This method was approved by the Expert Review Panel for Dietary Supplements as First Action.

The Expert Review Panel for Dietary Supplements invites method users to provide feedback on the First Action methods. Feedback from method users will help verify that the methods are fit-for-purpose and are critical for gaining global recognition and acceptance of the methods. 
Set 1 Ingredients (Anthocyanins, Chondroitin, and PDE5 Inhibitors) considered four methods for CS, and only the method developed by Ji et al. (2) was adopted for Official Methods First Action status.

\section{SMPR 2014.009 and LC Method}

The LC method and its single-laboratory validation (SLV) were first described in 2007 (2) and in 2015 were submitted to the ERP for SPDS Set 1 Ingredients in response to the call for methods. Briefly, $200 \mathrm{mg}$ of raw material, ground tablets, or ground capsule contents is dissolved in $100 \mathrm{~mL}$ water with sonication and filtered if needed. Liquid formulations (200 $\mathrm{mg}$ ) are diluted to $100 \mathrm{~mL}$ with water. The resulting test solution is subjected to hydrolysis with chondroitinase AC II to produce un-, mono-, di-, and trisulfated unsaturated disaccharides. Samples are then analyzed by ion-pairing reverse-phase LC with UV detection, and total CS is determined by summing the amounts of individual disaccharides.

SMPR 2014.009 (1) describes the minimum method performance requirements established by SPDS as summarized in Table 1. In a single-laboratory evaluation, methods must have an LOQ of $1 \%(\mathrm{w} / \mathrm{w})$; relative SD of repeatability of $₫ 3 \%$ in the low analytical range of $1-10 \%$ and $\_\%$ in the high analytical range of $>10-100 \%$; and recovery of $92-105 \%$ in the low range and $98-102 \%$ in the high range. The matrices to be included in the validation are tablets, capsules, softgels, gel caps, gummies, chewables, liquids, and powders.

The LC method was validated for raw material, capsules, chewables, tablets, softgels, and liquid supplements. Selectivity was evaluated by analyzing CS in the presence of other common dietary supplement ingredients including calcium sulfate, magnesium chloride, zinc chloride, cupric sulfate, glucosamine $\mathrm{HCl}$, methyl sulfonylmethane, chromium(III) chloride, dermatan sulfate, and carrageenan to look for interference with the method, either by deactivating the enzyme or interfering with the LC. Recoveries of CS varied from 97.3 to $102 \%$, demonstrating no interference from the ingredients tested. In addition, hyaluronic acid (HA) was analyzed by the method in the absence of CS and, as expected, produced a signal for $\triangle \mathrm{Di}-0 \mathrm{~S}$. HA is hydrolyzed by chondroitinase $\mathrm{AC}$ II to generate $\triangle \mathrm{Di}-0 \mathrm{~S}_{\mathrm{HA}}$, a diastereomer of $\triangle \mathrm{Di}-0 \mathrm{~S}$ that cannot be resolved under the LC conditions. Because HA is considerably more expensive than CS, however, it is unlikely to be used as an adulterant.

The linearity of the 5-point calibration curves was demonstrated over a range of $0.2-10$ $\mu \mathrm{g} / \mathrm{mL} \Delta \mathrm{Di}-0 \mathrm{~S}, 1.4-70 \mu \mathrm{g} / \mathrm{mL} \Delta \mathrm{Di}-4 \mathrm{~S}$, and $2-100 \mu \mathrm{g} / \mathrm{mL} \Delta \mathrm{Di}-6 \mathrm{~S}$ by showing no trend in the residual plots. Values for the coefficient of determination (r) were all $>0.999$.

Recovery was determined by spiking CS into raw material (heparin was used as a control raw material) and a non-CS commercial tablet product containing glucosamine $\mathrm{HCl}$ and methyl sulfonylmethane. Spiked raw material contained 33, 50, and $60 \%$ CS by weight, corresponding to 50,100 , and $200 \%$ of typical CS amounts in dietary supplements. Spiked finished product contained $16.7,28.6$, and $37.5 \%$ CS by weight, corresponding to 50,100 , and $150 \%$ of typical CS amounts in dietary supplements. Samples were analyzed in triplicate on 3 days. The method yielded recoveries of 100.8-101.6\% over the three levels in raw material and $105.4-105.8 \%$ over the three levels in finished product. Repeatability from 
the spiked samples was $0.98-2.8 \% \mathrm{RSD}_{\mathrm{r}}$ in raw material and $2.0-3.5 \% \mathrm{RSD}_{\mathrm{r}}$ in finished product.

Repeatability was determined in three raw materials, two tablets, capsules, chewables, softgels, and liquid supplements by testing four replicate preparations on either 1 or 3 days. Within-day repeatability ranged from 0.25 to $1.8 \% \mathrm{RSD}_{\mathrm{r}}$, between-day repeatability ranged from 1.32 to $4.66 \% \mathrm{RSD}_{\mathrm{r}}$, and total repeatability ranged from 1.60 to $4.72 \% \mathrm{RSD}_{\mathrm{r}}$. Interestingly, the liquid supplement was found not to contain CS, but, when spiked, yielded $99.6 \%$ recovery, demonstrating the applicability of the method to liquid supplements.

Finally, a Youden ruggedness trial demonstrated no effect from variation of seven parameters including sample sonication time, sample weight, enzyme hydrolysis time, enzyme concentration, enzyme buffer $\mathrm{pH}$, injection volume, and detector wavelength.

AOAC Official Method 2015.11 Chondroitin Sulfate Content in Raw Materials and Dietary Supplements High-Performance Liquid Chromatography with UV Detection After Enzymatic Hydrolysis First Action 2015

Refer to the published method for further details (2).

\section{Discussion}

Table 1 provides a comparison of the SMPR and the LC method SLV results. The validation study demonstrated acceptable results for within-day repeatability, although the range of total repeatability (within-day + between-day) exceeded the limit. Recovery was within the SMPR allowable range when spiked surrogate raw material was tested, but recovery from spiked finished product was slightly higher than the allowable range. After careful consideration, the ERP voted on August 3, 2015, to adopt the LC method for First Action Official Methods status.

Before obtaining Final Action status, the ERP recommended the following actions: (1) optimize and control the moisture in the CS including appropriate vessels and glassware; 2) investigate alternate LC columns; (3) optimize the LC conditions; (4) review lessons learned from the U.S. Pharmacopeia; (5) include a potency evaluation of the enzyme used; (6) investigate use of the currently available U.S. Pharmacopeia standard; and ( 7 ) use a certified reference material.

\section{Acknowledgments}

This work was supported by National Institutes of Health Office of Dietary Supplements Contract HHSN263201300015C.

\section{References}

1. AOAC SMPR 2014.009. J AOAC Int. 2014; 98:1058-1059.

2. Ji D, Roman M, Zhou J, Hildreth J. J AOAC Int. 2007; 90:659-669. [PubMed: 17580617] 


\section{Table 1}

SMPR 2014.009 requirements and Method 2015.11 results

\begin{tabular}{|c|c|c|c|c|}
\hline Type of study & Parameter & Minimum a & ceptable criteria & LC method results \\
\hline \multirow[t]{5}{*}{ Single-laboratory validation } & LOQ & \multicolumn{2}{|c|}{$1 \%(\mathrm{w} / \mathrm{w})$} & $\mathrm{NR}^{a}$ \\
\hline & Analytical range & $1-10 \%(\mathrm{w} / \mathrm{w})$ & $>10-100 \%(\mathrm{w} / \mathrm{w})$ & $5-100 \%$ \\
\hline & Repeatability $\left(\mathrm{RSD}_{\mathrm{r}}\right)$ & $3 \%$ & $\underline{2} \%$ & $0.25-1.8 \%$ within-day; $1.60-4.72 \%$ total \\
\hline & \multirow[t]{2}{*}{ Recovery } & \multirow[t]{2}{*}{$92-105 \%$} & \multirow[t]{2}{*}{$98-102 \%$} & $100.8-101.6 \%$ at $33-60 \%(\mathrm{w} / \mathrm{w}) \mathrm{RM}^{b}$ \\
\hline & & & & $105.4-105.8 \%$ at $16.7-37.5 \%(\mathrm{w} / \mathrm{w}) \mathrm{FP}^{\mathrm{c}}$ \\
\hline Multilaboratory validation & Reproducibility $\left(\mathrm{RSD}_{\mathrm{R}}\right)$ & $56 \%$ & $\leq 4 \%$ & $\mathrm{ND}^{d}$ \\
\hline
\end{tabular}

${ }^{a} \mathrm{NR}=$ Not reported.

$b_{\mathrm{RM}}=$ Raw material.

$c_{\mathrm{FP}}=$ Finished product.

${ }^{d} \mathrm{ND}=$ Not determined. 